\title{
Spontaneous reabsorption of a rubella cataract
}

\author{
George T H Smith, G Adrien Shun-Shin, Anthony J Bron
}

\begin{abstract}
A case of spontaneous reabsorption of a rubella cataract is presented. The morphology of the capsular bag is recorded by Scheimpflug slit image and retroillumination photography.
\end{abstract}

Rubella virus is a well established cause of congenital cataract, ${ }^{1-4}$ the virus sometimes being cultured from the lens for as long as $\mathbf{3 0}$ months after birth. ${ }^{2}$ Spontaneous reabsorption of cataract when the capsule is apparently intact is a rare event in humans. ${ }^{45}$

\section{CASE REPORT}

A baby boy presented in January 1974 aged 6 weeks when it was noticed that the right pupil was larger than the left.

On examination his left eye was microphthalmic and he had an immature cataract. The red reflex was present, though funduscopy was not possible. The right lens was clear, and funduscopy revealed a pigmentary retinopathy on that side. Surgery was not carried out, because lensectomy for a unilateral cataract was thought to carry a poor visual prognosis, especially in an eye that was microphthalmic.

His mother was believed to have had rubella at two weeks of gestation. The baby had a rubella titre of $1 / 512$ in January 1974 , but virus was not isolated from his tears.

Followed up at regular intervals in the clinic, he subsequently developed a rotary nystagmus and a left esotropia. Over the years it has been recorded that his left lens has become progressively thinner, and when he was reviewed in October 1988 the lens was described as being 'biscuit' shaped, with white flecks deposited inside the shrivelled capsular bag (Figs 1 and 2).

At his last attendance in October 1989 the anterior and posterior capsules were in apposition. The Scheimpflug photograph in Fig 3 shows the two leaves of the anterior and posterior capsule. The arrows point to intense scatter anterior and posterior to the opacities. Funduscopy was now possible, and a typical salt and pepper pigmentary retinopathy was observed.

The patient continues to manage well with a right visual acuity of $6 / 12$. The vision in his left eye remains poor at counting fingers as a result of macular damage and dense amblyopia. He also suffers from sensorineural hearing loss and had a small ventricular septal defect diagnosed at birth.

Street, Oxford

Street, Oxford OX2 6AW.

G T H Smith

G A Shun-Shin

A J Bron

Correspondence to:

George T H Smith, FRCS,

Clinical Cataract Research

Unit, Nuffield Laboratory of Ophthalmology, Walton Street, Oxford OX2 6AW

Accepted for publication 10 April 1990

Rubella cataracts occur in approximately $50 \%$ of cases of congenital rubella. The cataracts are bilateral in about $70 \%$ of cases and usually involve the nucleus, which is opaque. ${ }^{23}$ The cataract may be associated with pigmentary

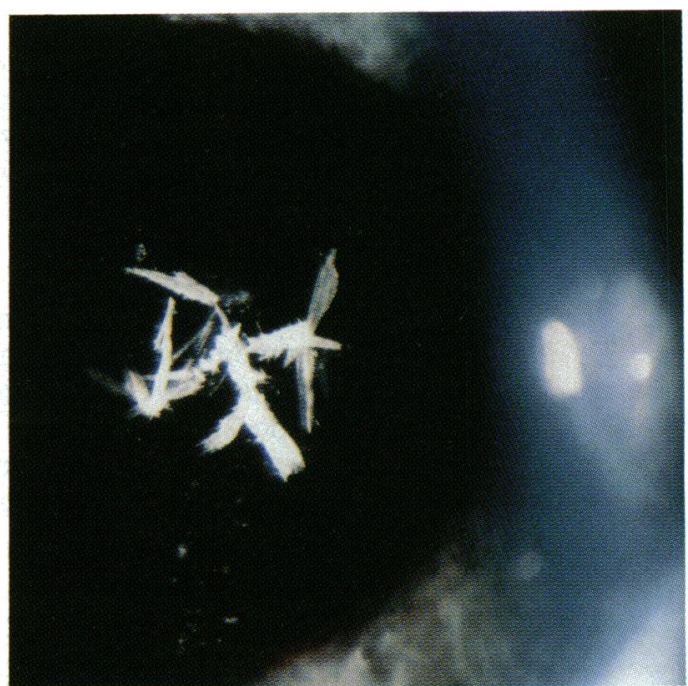

Figure 1: Colour photograph showing the white crystals which remained in the capsular bag after the cataract had been reabsorbed.

retinopathy, microphthalmia, mesodermal dysgenesis, glaucoma, strabismus, and nystagmus. ${ }^{3}$

Possible spontaneous reabsorption of rubella cataract has been reported. ${ }^{16-8}$ Ehrlich' reported a bilateral case in 1948 and described how on needling the remaining membrane no cortical matter was found and a clear pupil was achieved. His case was well documented, and he describes how the cataracts developed from being immature on presentation to becoming mature and then subsequently reabsorbing.

Gamble, ${ }^{6}$ Blake, ${ }^{7}$ and Long and Davidson ${ }^{8}$ also describe their cases as being membranous but do not describe any progression from immaturity through maturity to becoming membranous. Blake suggested that his case might have been as a result of failure of lens fibres to develop rather than reabsorption.

The cause of spontaneous reabsorption of

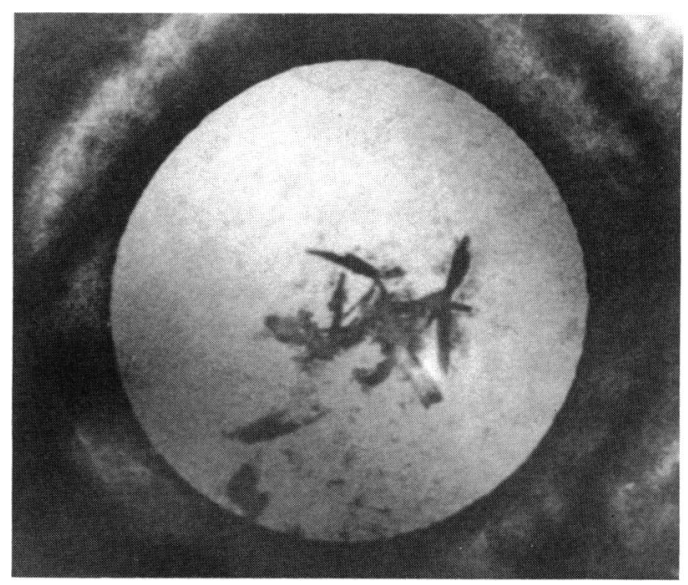

Figure 2: Retroillumination photograph showing the crystals silhouetted against the red reflex. 


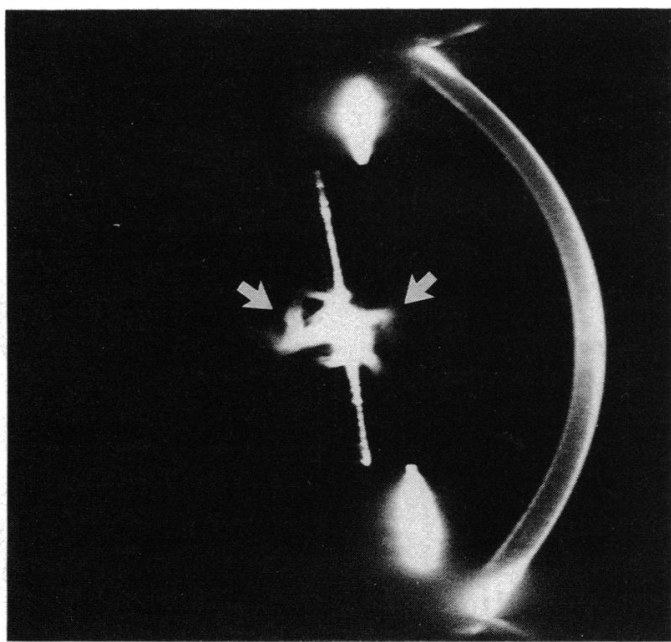

Figure 3: Scheimpflug photograph demonstrating the capsular bag. The arrows point to areas of intense scatter anterior and posterior to the white opacities.

cataract is unknown. It is well known that reabsorption can occur after rupture of the capsule, ${ }^{4}$ but it is much more difficult to understand the mechanism in cases where the capsule remains intact. Possibly endogenous proteinase activity is responsible for the breakdown of the lens proteins, which can then leak out of an intact capsule. ${ }^{910}$ Total reabsorption of a cataract is much more likely to occur in children than in adults, as the nucleus is more readily digested in immature lenses. ${ }^{10}$
The nature of the white crystals that remain within the capsular bag is uncertain, but they probably contain calcium oxalate as a result of dystrophic calcification. ${ }^{510}$

Scheimpflug and retroillumination photography are well recognised techniques for looking at the human lens in vivo. ${ }^{11-14}$ In this case they clearly demonstrate the end result of spontaneous reabsorption of a congenital cataract due to rubella.

1 Ehrlich LH. Spontaneous absorption of congenital cataract following maternal rubella. Arch Ophthalmol 1948; 39: 205-9.

2 Bellows JG. Cataract and abnormalities of the lens. New York: Grune and Stratton, 1975: 206-13.

3 Duane TD. Clinical ophthalmology. Philadelphia: Harper and Row, 1987; 5: chapter 41:4.

4 Duke-Elder S. System of ophthalmology. X1, Diseases of the lens and vitreous. London: Kimpton, 1969; 11: 138, 220-3.

Zimmerman LE, Hogan MJ. Ophthalmic pathology, an atlos and textbook. 2nd ed. Philadelphia: Saunders, 1962: 668-9.

6 Gamble RC. Membranous cataract due to rubella in the mother. Am F Ophthalmol 1946; 29: 737-8.

7 Blake EM. Congenital membranous cataract. Am f Ophthal-

mol 1946; 29: 464.
8 Long JL, Davidson RU. Cataracts and other congenital defects in infants following rubella in the mother. Arch defects in infants following

9 Trayhurn P, Van Heyningen R. Neutral proteinase activity in the human lens. Exp Eye Res 1976; 22: 251-7.

10 Bron AJ, Habgood JO. Morgagnian cataract. Trans Ophthalmo Soc UK 1976; 96: 265-76.

11 Brown NAP. Slit image photography. Trans Ophthalmol So UK 1969; 89: 397-408.

12 Brown NAP. Quantitative slit image photography of the lens. Trans Ophthalmol Soc UK 1972; 92: 303-17.

13 Brown NAP. The Oxford retro-illumination cataract recording camera - a new instrument. $\mathcal{F}$ Audiov Media Med 1988; 11: $58-60$.

14 Kawara T, Obazawa H. A new method for retro-illumination photography of cataractous lens opacities. Am $\mathcal{F}$ Ophthalmol 1980; 90: 186-9. 